\title{
Determinant of time-to-first birth interval after marriage among Ethiopian women
}

\author{
Ayele Gebeyehu Chernet ${ }^{1 *}$ (D), Dinberu Seyoum Shebeshi ${ }^{2}$ and Akalu Banbeta ${ }^{2}$
}

\begin{abstract}
Background: Time-to-first birth after marriage has a significant role in the future life of each individual woman and has a direct relationship with fertility. This study aimed to see the determinant of time-to-first birth interval after marriage among Ethiopian women.

Methods: The data was obtained from 2011 Ethiopia Demographic and Health Survey which is the third survey. The sample was selected using a stratified; two-stage cluster sampling design and the data was analysed using parametric shared frailty model.

Results: A total of 7925 ever married women from the nine region of the country were included in this study. Of the total women, 5966 (75.3\%) of them gave firstbirth. Age, residence area, employment status, contraceptive use and education of women were associated significantly to time-to-first birth.

Conclusions: Women having younger age at first marriage, urban women, contraceptive users had prolonged time to first birth interval. There is a need of teaching family for contraceptive use and improving women education to increase the length of first birth interval in Ethiopia.
\end{abstract}

Keywords: Frailty, First birth interval, Acceleration factor, Ethiopia

\section{Background}

The first visible outcome of the fertility process is the birth of the first child. The first birth marks a woman's transition into motherhood. It plays a significant role in the future life of each individual woman and has a direct relationship with fertility [1]. The timing of the first birth influences the number of children a woman bears throughout her reproductive period in the absence of any active fertility control, and woman who starts giving the first birth very early in life tends to have a large number of children than those who starts late [2].

Fertility patterns in the world have changed dramatically over the last two decades since the international conference on population and development (ICPD) in 1994, producing a world with very diverse child bearing patterns [3]. Many countries in Asia were able to reduce their fertility through government policies. For instance, China and Vietnam have witnessed declines in their total fertility rate (TFR) due to stringent government policies

\footnotetext{
*Correspondence: gebeyehu29@gmail.com

${ }^{1}$ Department of Statistics, College of Natural and Computational Sciences, Wolkite University, Wolkite, Ethiopia

Full list of author information is available at the end of the article
}

that discourage early and arranged marriage [4]. However, the delayed fertility transition has been observed to be underway in the region with remarkable progress in African countries like South Africa, Botswana, and Zimbabwe [5], fertility remains high in Africa by the standards of the rest of the world.

Fertility rates in sub Saharan Africa have been identified to exhibit a very unique demographic scenario in the world that sets it apart from other regions in the world. Contrary to the case of most regions like Europe, South America and Asia that have for long entered the fertility transition marked by a declined in their fertility rates in the 1950s and 1960s, sub-Saharan Africa is the only region in the world, where fertility decline has been rather slow and late [6]. Fertility rates in the subcontinent stand at the same level as that of Asia and South America towards the end of the 1970s. Most countries in Sub Saharan Africa are still experiencing relatively higher fertility rates. What can be discern from the information so far provided, is that sub-Saharan Africa is the sole region in the world that has not so far experienced any significant decline in its fertility rates [7]. 
According to United Nations 2014 report, 45 out of 66 high fertility countries (more than 3.2 children per woman) are increasingly concentrated in sub-Saharan Africa [3].

Ethiopia is the second most populous countries in sub-Saharan Africa next to Nigeria with 94,351,001 population size and 29 years of doubling time along with the scarcity of resources [8]. Uncontrolled fertility has adversely influenced the socio-economic, demographic and environmental development of the country. Poverty, war and famine, associated with low levels of education and health, a weak infrastructure, and low agricultural and industrial production have aggravated the problem of overpopulation [9]. When we look back at the history of Ethiopia population growth rate, there has been a steady increase since 1960. Based on 1984 census information, population growth rate was estimated at about $2.3 \%$ for the $1960-70$ period, $2.5 \%$ for the $1970-80$ period, and $2.8 \%$ for the $1980-85$ period. Population projections compiled in 1988 by the CSA projected a $2.83 \%$ growth rate for $1985-90$ and a $2.96 \%$ t growth rate for 1990-95. According to the 2007 Ethiopia population census, the annual population growth rate within 19942007 was estimated as $2.6 \%$.

Age at the start of marriage is one of determinant factors. Early childbearing can interrupt a young women's education and other activities which women need to accomplish [3]. Other major social, economic and cultural factors which are related to family and reproduction status, as well as personal values and practices, are shown to influence fertility and thus time to first birth $[4,5]$.

But the fertility rate is quite different across different customs, culture and practice of people living in different regions of Ethiopia. This implied that the existence of heterogeneity in the survival of time-to-first birth between different regions. For the formulation of effective policy to motivate people for longer first birth interval after marriage, it is crucial to study the effect of various socio-economic and demographic factors which affect time-to-first birth. Having these, this research aimed to examine factors associated to time-to-first birth interval after marriage using parametric shared frailty survival models.

\section{Methods}

\section{Study population and sampling design}

The data was obtained from 2011 EDHS, which was taken from Central Statistical Agency (CSA). Each region of Ethiopia was stratified into urban and rural areas resulting 21 sampling strata. Enumeration Areas (EAs) were selected independently in each stratum in two stages. In the first stage, a total of 645 EAs (202 EAs in urban areas and 443 EAs in rural areas) were selected with probability proportional to the EA size (based on the 2007 Population and House Census) and with independent selection in each sampling stratum. The resulting lists of households served as a sampling frame for the selection of households in the second stage. In the second stage of selection, a fixed number of 28 households per cluster were selected with an equal probability systematic selection from the newly created household listing.

The questionnaires for data collection were adapted from model survey instruments developed for the measure DHS project to reflect the population and health issues relevant to Ethiopia. The questionnaires were developed in English and translated into three major local languages-Amharic, Oromiffa, and Tigrigna. A representative sample of 17,817 households were selected, of these, 16,702 were successfully interviewed. In the interviewed households 17,385 eligible women were identified for individual interview; complete interviews were conducted for 16,515. After excluding missing values, a total of 7925 with women were included [10].

\section{Variables and statistical analysis Response variable}

The response variable is time-to-first birth among woman in Ethiopia, which is measured in months. For women who did not give birth (censored) the time was measured till the date of the interview. Independent Variables: Independent variables included in the analysis are described in Table 1 as follows.

\section{Statistical analysis}

Descriptive analysis was performed using frequency and percentage for both dependent and independent variables. Parametric Shared Frailty survival model was used to identify significant factors of FBI by considering region of women as clustering variable because fertility rate is different due to the presence of different custom; culture and practice of people across regions of the country. The shared frailty approach assumes that all FBI in a cluster are conditionally independent given the frailties. The value of the frailty term is constant over time and common to all individuals in the cluster, and thus it is responsible for creating dependence between event times in a cluster [11, 12].

Akaike's information criterion (AIC) was used for model comparison. Data cleaning, management and analysis were carried out using STATA, Version 12. All hypotheses testing to determine differences, associations and relationships were judged significant at $p<0.05$.

\section{Inclusion exclusion criteria}

Women who went into marriage for the first time without a child or no pregnancy and with complete records were considered. Thus, women having less than nine 
Table 1 Description of independent variables used in the analysis

\begin{tabular}{|c|c|c|}
\hline Variables & Description & Categories \\
\hline age & Age of women at marriage & Measured in years \\
\hline Women education & Women's level of education & $\begin{array}{l}0=\text { No education; } 1=\text { Primary } \\
2=\text { Secondary \&above }\end{array}$ \\
\hline Husband education & Husband's level of education & $\begin{array}{l}0=\text { No education; } 1=\text { Primary } \\
2=\text { Secondary and above }\end{array}$ \\
\hline Wealth index & Household wealth index & $0=$ Poor $; 1$ = Meddle; 2 = Rich) \\
\hline Place of residence & Place of residence & $0=$ Rural; $1=$ Urban) \\
\hline Mass media & Access to mass media & $0=\mathrm{No} ; 1=$ Yes \\
\hline Employment & Employment status & $0=$ unemployed $1=$ Employed \\
\hline Contraceptive & Use of Contraceptive & $0=$ Non-User, $1=$ User \\
\hline Religion & Religion of respondents & $0=$ Muslim, $1=$ Orthodox, $2=$ Protestant, $3=$ Other \\
\hline Region & Region of respondents & $\begin{array}{l}\text { Tigray, Afar, Amhara, Oromia, Somali, Benishangul, } \\
\text { SNNPR, Gambela, Harari, Addis Ababa, Dire Dawa }\end{array}$ \\
\hline
\end{tabular}

Region of the women was considered as a clustering effect in frailty model

months of waiting time for first birth after marriage and having negative birth interval were excluded.

\section{Limitation of study}

This research excluded Somali region because the data cannot be considered as representatives of the region since some EAs are not interviewed due to drought and security problems. And also some factors which may have significant contribution to FBI such as age at menarche and menstrual status were not considered. Investigating the influence of these factors may be appropriate to understand further dynamics of time to first birth after marriage in the country. In addition to this, further studies should be warranted in each region of Ethiopia and explore other factors that are not addressed in this study.

\section{Results}

A total of 7925 women who got first marriage from eight regional states and two administrative cities of Ethiopia were included. Of the total women, 5966 (75.3\%) of them gave first birth while 1959 (24.7\%) of them did not give birth until the end of the interview (Table 2). The median time of FBI and age of women at first marriage were estimated to be 30 months and 16 years respectively.

The median survival time to first birth with the corresponding 95\% confidence interval for all region of the country was presented in Table 3 . The maximum and minimum median time to first birth for women was from Amhara (51 months) and SNNP (23 months) region respectively.

The result of log-normal gamma shared frailty model was presented in Table 4. The age of women at marriage was statistically significant to determine time-to-first birth after marriage, the acceleration factor $(\phi=0.927$,
95\% CI: 0.922-0.932). Accordingly, as age of women at first marriage increases, the time-to-first birth becomes shorter by a factor of $\phi=0.927$.

Urban women have prolonged time-to-first birth than women from rural by a factor of $\phi=1.292$. Employed women prolonged time-to-first birth than unemployed women by a factor of $\phi=1.080$ with $95 \%$ CI: 1.042 1.120. Mothers who used contraceptive methods prolonged time-to-first birth by a factor of $\phi=1.116$ (95\% CI: 1.072-1.162) as compared to non-users. Women who attended secondary education and above had shorten time-to-first birth by a factor of $\phi=0.828$ with $95 \%$ confidence interval $(0.796,0.862)$ as compared to the uneducated women. The variance of the frailty distribution $(\boldsymbol{\theta}=0.78)$ had significant contribution to the model that indicates the presence of heterogeneity among timing of first birth among the regions.

\section{Discussion}

This study applied parametric survival frailty models in order to investigate the determinant factors of time-tofirst birth after marriage among Ethiopian women, based EDHS 2011 data set. 7925 Ethiopian women who got an official marriage were included in the study. The prevalence of having the first child after marriage was $75.3 \%$. Graphically it could be observed that high rate of first birth within the first three years following the marriage. This finding similar to the previous community based cross-sectional study in Lemo district, Ethiopia [1]. Previous study in Sub-Saharan level was established that $57 \%$ of women of child bearing age in 2002 practiced time to first birth less than 3 years [6]. This may be due to the reason that many women in developing countries do not use contraception after birth and therefore are likely to become pregnant once fecundity achieved [13]. 
Table 2 Baseline covariates characteristics with their time-to-event status

\begin{tabular}{|c|c|c|c|c|}
\hline \multirow[b]{2}{*}{ Variable } & \multirow[t]{2}{*}{ Categories } & \multirow[t]{2}{*}{ Total (\%) } & \multicolumn{2}{|l|}{ Status } \\
\hline & & & Censored (\%) & Event (\%) \\
\hline \multirow[t]{2}{*}{ Place of Residence } & Rural & $5969(75.3)$ & 1155 (19.4) & 4814 (80.6) \\
\hline & Urban & $1956(24.7)$ & $804(41.1)$ & $1152(58.9)$ \\
\hline Wealth Index of & Poor & $3310(41.8)$ & $608(18.4)$ & 2702 (81.6) \\
\hline \multirow[t]{2}{*}{ Family } & Middle & $1260(15.9)$ & $244(19.4)$ & 1016 (80.6) \\
\hline & Rich & $3355(42.3)$ & 1107 (33) & $2248(67)$ \\
\hline \multirow[t]{2}{*}{ Contraceptive Use } & Use & $5901(74.5)$ & $1514(25.7)$ & $4387(74.3)$ \\
\hline & Not Use & $2024(25.5)$ & $445(22)$ & $1579(78 \%)$ \\
\hline Employment status of & Yes & $2935(37.0)$ & 966 (32.9) & $1969(67.1)$ \\
\hline Women & No & $4990(63)$ & $993(19.9)$ & $3997(80.1)$ \\
\hline \multirow[t]{4}{*}{ Religion } & Muslim & $2925(36.9)$ & $579(19.8)$ & $2346(80.2)$ \\
\hline & Orthodox & $3220(40.6)$ & 1017 (31.6) & $2203(64.4)$ \\
\hline & Protestant & $1535(19.4)$ & $312(20.3)$ & $1223(70.7)$ \\
\hline & Other & $245(3.1)$ & $51(20.8)$ & $194(79.2)$ \\
\hline \multirow[t]{2}{*}{ Mass Media } & No & 4585 (57.9) & $986(21.5)$ & 3599 (78.5) \\
\hline & Yes & $3340(42.1)$ & $973(29.1)$ & $2367(70.9)$ \\
\hline Women's' Education & No education & $5108(64.4)$ & $1169(22.9)$ & $3939(77.1)$ \\
\hline \multirow[t]{2}{*}{ Level } & Primary & $2159(27.2)$ & $507(23.5)$ & $1652(76.5)$ \\
\hline & Secondary \& above & $658(8.3)$ & $283(43)$ & $375(57)$ \\
\hline Husband's Education & No education & $3857(48.7)$ & $939(24.3)$ & 2918 (75.6) \\
\hline \multirow[t]{2}{*}{ level } & Primary & $2855(36.0)$ & $569(19.9)$ & $2286(80.1)$ \\
\hline & Secondary\& above & $1213(15.3)$ & $451(37.2)$ & $762(62.8)$ \\
\hline Total & & & $1959(24.7)$ & $5966(75.3)$ \\
\hline
\end{tabular}

The estimated median age of women at marriage was 16 years. This result is consistent withstudy conducted in the county where $60.6 \%$ of Ethiopian women were married before the ageof 18 years [14].

The estimated median survival time of first birth after marriage of Ethiopian women is found to be 30 months. This finding is almost similar with the finding for the

Table 3 Median survival time (in months) of first birth by

\begin{tabular}{lll} 
region & Number of women (\%) & Median (IQR) \\
\hline Region & $548(6.9)$ & $37(50)$ \\
Addis Ababa & $718(9.1)$ & $26(31)$ \\
Amhara & $1166(14.7)$ & $51(61)$ \\
Beninshangul- Gumuz & $684(8.6)$ & $33(51)$ \\
Dire-Dawa & $516(6.5)$ & $30(41)$ \\
Gambela & $636(8.0)$ & $31(41)$ \\
Harari & $543(6.9)$ & $28(51)$ \\
Oromiya & $1203(15.2)$ & $24(26)$ \\
SNNP & $1092(13.8)$ & $23(25)$ \\
Tigray & $819(10.3)$ & $37(46)$
\end{tabular}

IQR Inter Quartile Range same country using 2005 EDHS [15] and result revealed that the median time of FBI was 29 months. This estimate is also exactly identical to Ghanaian women [16]. However, the median time of FBI is a bit lower than women in Bangladesh where it was estimated to be 25 months [17]. This difference may be due to the practice of early marriage in Ethiopia which had potential to prolong timing of first birth [15].

Marriage at older age significantly associated with shorter time interval for the first birth. This result is consistent with the study in the country and abroad [18, 19]. The reason may be older women need to give birth soon after marriage to have the desired number of children before the end of their reproductive life. And, woman who gets early marriage use contraceptive to elongate time-to-first birth until it becomes physically mentally matured [17]. However, some contradictory results were also observed such as in Pakistan, younger women at marriage had shorter FBI [20].

The results of this study suggested that women who lived in urban areas had longer first birth interval than women who lived in rural areas. Rural inhabitants have usually no access for maternal health and family planning programs as compared to urban residents [15] 
Table 4 Results of log-normal gamma shared frailty model

\begin{tabular}{|c|c|c|c|c|c|c|}
\hline Covariate & Category & Estimate $(\hat{\beta})$ & $\operatorname{SE}(\hat{\beta})$ & $\varphi$ & $95 \% \mathrm{Cl}$ & $P$-value \\
\hline Age & & -0.08 & 0.0027 & 0.927 & {$[0.922,0.932]$} & $0.000^{*}$ \\
\hline Place of & Rural & Ref. & & & & \\
\hline Residence & Urban & 0.26 & 0.0250 & 1.292 & {$[1.231,1.357]$} & $0.000^{*}$ \\
\hline Employment & Unemployed & Ref. & & & & \\
\hline Status & Employed & 0.08 & 0.0180 & 1.080 & {$[1.042,1.120]$} & $0.000^{*}$ \\
\hline \multirow[t]{2}{*}{ Contraceptive } & Non- User & Ref. & & & & \\
\hline & User & 0.11 & 0.0206 & 1.116 & {$[1.072,1.162]$} & $0.000^{*}$ \\
\hline Women & No education & Ref & & & & \\
\hline \multirow[t]{2}{*}{ Education } & Primary & -0.19 & 0.0204 & 0.828 & {$[0.796,0.862]$} & $0.000^{*}$ \\
\hline & Sec \& above & -0.05 & 0.0395 & 0.956 & {$[0.885,1.033]$} & 0.259 \\
\hline$\theta=0.78$ & $\lambda=2.541$ & & & & likelihood $=-813.8$ & \\
\hline$\tau=0.28$ & $\rho=3.185$ & & & & $\mathrm{AIC}=13,641.69$ & \\
\hline
\end{tabular}

$\phi$ Indicates Acceleration factor; ${ }^{*}$ significant at 5\% level; $95 \% \mathrm{Cl}$ : $95 \%$ confidence interval for acceleration factor; $\mathrm{SE}(\hat{\beta})$ : standard error for $\hat{\beta}$; Ref. Reference

which may results in short birth interval. This finding is supported by a study in Bangladeshi study and a longitudinal data based study in Nigeria $[16,17]$. Another important finding of this study was that employment status of the women had a significant association to time-to-first birth. Time-to-first birth interval following marriage for employed women was longer than unemployed women. This is consistent with studies which were done abroad $[21,22]$. Women those used contraceptive had long time-to-first birth than the non-users. This is due to contraceptive service which helped them to protect early and unwanted pregnancy in marriage life of the couples [17]. A similar study in India reported that contraceptive use did not emerge as a significant associated factor at any birth interval [23].

A significant association was found between women education and time-to-first birth. Women with secondary and above education have significant shorter first birth interval as compared to women who were not educated. This may be due to the reason that at the time of entry to marriage life, educated women can be emotionally prepared, biologically matured, and financially secured to have a child. A study in India established that education of women was significantly associated with first birth interval only while husband's education was significantly associated with first and second birth interval [23]. In another study on timeto-age at first birth in Ethiopia, they established that educated women have longer waiting time to time-tofirst birth after marriage. When women spend a longer time at school, this is likely to significantly affect both age at marriage and the duration between marriage and the first birth [24].

\section{Conclusions}

The study aimed to examine time-to-first birth interval after marriage and its associated factors among Ethiopian women using Parametric Shared Frailty Model. A total of 7925 woman who got involved in first marriage from the nine region of the country included in this study. The median survival time of FBI was estimated to be 30 months. Younger age, residence area, employment status, contraceptive use and education status of woman associated significantly to time to FBI. There is a need of teaching family for contraceptive use and improving woman education to increase the length of FBI along with not encouraging early marriage to get control a rapid population growth in Ethiopia.

\section{Abbreviations \\ ANC: Antenatal Care; CSA: Central Statistical Agency; EAs: Enumeration Areas; EDHS: Ethiopian Demographic and Health Survey; FBI: First Birth Interval; HH: Household; SE: Standard Error; WHO: World Health Organization}

\section{Acknowledgements}

We would like to thank CSA of Ethiopia for giving the data.

\section{Authors' contributions}

AG wrote the proposal collects data from CSA and analysed the data in consultation with the DS and $A B$. DS and $A B$ edited the document and gave critical comments. All authors read and approved the final manuscript.

\section{Funding}

No funding was obtained for this study.

\section{Availability of data and materials}

The dataset was demanded and retrieved from CSA website after formal online registration and submission of the project title and description. The data can be accessed through http://www.statsethiopia.gov.et/.

Ethics approval and consent to participate

Ethics approval and participant consent were not necessary as this study used previously-published database by CSA of Ethiopia. 


\section{Consent for publication}

Not applicable.

\section{Competing interests}

The authors declare that they have no competing interests.

\section{Author details}

'Department of Statistics, College of Natural and Computational Sciences, Wolkite University, Wolkite, Ethiopia. ${ }^{2}$ Department of Statistics, College of Natural and Computational Sciences, Jimma University, Jimma, Ethiopia.

Received: 31 January 2019 Accepted: 27 November 2019

Published online: 10 December 2019

\section{References}

1. Tadesse F, Headey D. Urbanization and fertility rates in Ethiopia (No. 35). International Food Policy Research Institute (IFPRI); 2012.

2. Gyimah SO. A cohort analysis of the timing of first birth and fertility in Ghana. Popul Res Policy Rev. 2003;22(3):251-66.

3. United Nations. World Fertility Report: Fertility at the Extremes. New York: Population Division of the Department of Economic and Social Affairs of the United Nations Secretariat; 2014.

4. Löfstedt P, Ghilagaber G, Shusheng L, Johansson A. Changes in marriage age and first birth interval in Huaning County. PR China: Yunnan Province; 2005.

5. Bongaarts J. Fertility transitions in developing countries: Progress or stagnation? Stud Fam Plan. 2008;39(2):105-10.

6. Moultrie TA, Sayi TS, Timæus IM. Birth intervals, postponement, and fertility decline in Africa: A new type of transition? Popul Stud. 2012;66(3):241-58.

7. Malmberg B. Demography and the development potential of sub Saharan Africa; 2008

8. Ekane D. Fertility trends in sub Saharan Africa. Stockholm: Stockholm University; 2013.

9. Ezra M. Demographic responses to environmental stress in the drought-and famine-prone areas of northern Ethiopia. Int J Popul Geogr. 2001;7(4):259-79.

10. Central Statistical Agency [Ethiopia] and ICF International. Ethiopia Demographic and Health Survey 2011. Addis Ababa: Central Statistical Agency and ICF International; 2012.

11. Kleinbaum DG, Klein M. Survival analysis. New York: Springer-Verlag; 1996. p. 86-128.

12. Muche R. Applied Survival Analysis: Regression Modeling of Time to Event Data. In: Hosmer Jr DW, Lemeshow S, editors. . New York: John Wiley; 1999. p. 386. US \$89.95. ISBN: 0-471-15410-5. (2001) International Journal of Epidemiology, 30(2), 408-409.

13. Abdel-Tawab, Nahla G., Sarah Loza, and Amal Zaki. Helping Egyptian women achieve optimal birth spacing intervals through fostering linkages between family planning and maternal/child health services. FRONTIERS Final Report. Washington, DC: Population Council; 2008.

14. Tessema B, Ayalew S, Mohammed K. Modeling the determinants of time-toage at first marriage in Ethiopian women: comparison of various parametric shared frailty models. Sci J Public Health. 2015;3(5):707-18.

15. Wondiber $\mathrm{N}$. The statistical distribution and some determinants of birth interval for rural Ethiopia; 2015.

16. Logubayom IA, Luguterah A. Survival analysis of time to first birth after marriage. Res Humanit Soc Sci. 2013;3(12):117-25.

17. Amusan AS, Mohd KZ. Survival Modeling of First Birth Interval After Marriage. Life Sci J. 2014;11(7):299-307.

18. Joshi S, Schultz TP. Family planning and women's and children's health: Long-term consequences of an outreach program in Matlab, Bangladesh. Demography. 2013;50(1):149-80.

19. Alemayehu T, Haidar J, Habte D. Determinants of exclusive breastfeeding practices in Ethiopia. Ethiopian journal of health. Development. 2009;23(1): 772-80.

20. Kamal A, Pervaiz MK. Determinants of Marriage to First Birth Interval in Pakistan. J Stat. 2013;20(1):44-68.

21. Hidayat $R$, Sumarno $H$, Nugrahani EH. Survival analysis in modeling the birth interval of the first child in Indonesia. Open J Stat. 2014;4(03):198.

22. Islam MS. Differential determinants of birth spacing since marriage to first live birth in rural Bangladesh. Pertanika J Soc Sci Hum. 2009;17(1):1-6.

23. Singh $R$, Tripathi $V$, Kalaivani $M$, Singh $K$, Dwivedi SN. Determinants of birth intervals in Tamil Nadu in India: developing Cox hazard models with validations and predictions. Revista Colombiana de Estadística. 2012;35(2): 289-307.

24. Yohannes S, Wondafrash M, Abera M, Girma E. Duration and determinants of birth interval among women of child bearing age in southern Ethiopia. BMC Pregnancy Childbirth. 2011;11(1):38.

\section{Publisher's Note}

Springer Nature remains neutral with regard to jurisdictional claims in published maps and institutional affiliations.

\section{Ready to submit your research? Choose BMC and benefit from:}

- fast, convenient online submission

- thorough peer review by experienced researchers in your field

- rapid publication on acceptance

- support for research data, including large and complex data types

- gold Open Access which fosters wider collaboration and increased citations

- maximum visibility for your research: over $100 \mathrm{M}$ website views per year

At $\mathrm{BMC}$, research is always in progress.

Learn more biomedcentral.com/submissions 